\title{
VIBRATION-BASED DAMAGE DETECTION OF BEAM-LIKE STRUCTURES USING DISCRETE WAVELET TRANSFORM
}

UDC: $534-16$

Original scientific paper

https://doi.org/10.18485/aeletters.2018.3.4.1

\author{
Lanka Ramesh $^{1 *}$, Putti Srinivasa Rao ${ }^{2}$ \\ ${ }^{1}$ Gudlavalleru Engineering College, Mechanical Engineering Department, Gudlavalleru, India \\ ${ }^{2}$ Andhra University, Mechanical Engineering Department, Visakhapatnam, India
}

\begin{abstract}
:
In this paper, a new modal parameters-based damage detection method has been proposed for accurate characterization of single and multi-surface cracks in beam-like structure. The advantage of this method is undamaged mode profiles from the damaged mode profiles of beam structure. For that, curve fitting (CF) analysis was used to extract the undamaged mode profiles from damaged one. Discrete Wavelet transformation (DWT) method is presented to demonstrate effectiveness of the proposed approach without use of base line data as a reference. To illustration of this method, numerical and experimental modal analysis is performed on two aluminum cantilever beams containing single and double cracks to examine the location and quantification of different damage scenarios. First five modal frequencies and mode profiles are employed to assess the effectiveness of the proposed method. Moreover, to validate the accuracy of the proposed approach in damage identification, established results have been balanced with other experimental based results, which were found in the literature. From the results, it can be seen that damage scenarios of the two beams are quite different the chosen methods precisely identify the location and quantification of the damage in beam structures. It is concluded that composed mode profiles by the proposed approach can be conveniently used as reference data for the damage identification purpose.
\end{abstract}

\section{ARTICLE HISTORY}

Received: 07.11.2018.

Accepted: 19.12.2018.

Available: 31.12.2018.

\section{KEYWORDS}

Beam-like structure, mode profiles, Mode shape curvature, Experimental Modal Analysis, discrete Wavelet Transform

\section{INTRODUCTION}

The structural damage detection in civil, mechanical, marine, and aerospace structures is plays essential role in not only the health analysis and estimation of its lifespan, but also estimating the eventual expenditure and planning for overhaul appropriately. Structural Health Monitoring (SHM) is a non- destructive damage detection strategy for structures to assess their condition in response to the structure. Recent decades SHM plays essential role in assuring the structural integrity.

In this scenario, damage is defined as the changes in dynamic parameters of vibrational structure that suspiciously influence the structure's functioning. Damage is also defined as changes in the geometries, which lead to inadmissible internal stresses, excessive deflections or vibrations in the structural components/system. These instabilities are due to the internally generated cracks, corrosive spots, loosening of mated parts in a system, ageing of structure and fatigue, etc. In past few years, many researchers have been developed sophisticated dynamic damage identification methods, which the related literature is substantial. The basic idea of elemental or essential assertion in vibration-based damage detection (VBDD) approaches is that changes in physical properties such as mass, damping, stiffness, etc. will alter the 
dynamic responsive modal parameters of the structure, such as modal frequencies, mode profiles or modal displacements, mode shape derivatives, modal energy changes, etc. have been found in the literature [1-13]. These changes contribute as ingredients to evaluating integrity of the structure.

The methods using measurement of lower structural frequency changes can be used to identify locate and estimate severity of the damages in the structures as a NDT technique. This method can be applied to any kind the structures without need to measured healthy structure data [1-2]. However, change in frequency itself may be provided information regarding the presence damage in the structure but not the location and quantification of damage. In the recent years an extensive literature reviews have been published on various damage detection methods and health monitoring of structures based on vibrational dynamic parameters i.e. natural frequencies, modal displacements, and ratios of modal damping values, etc. [3-5].

Furthermore, the existence the damage in the structure not only leads to change global dynamic characteristics but also locally around the area of damage, which causes to alter both global and local, the strain energy of the structure. Cornwell et al. [6] utilized the experimental and numerical modal parameters to detect the damages in structural plate-like members based on the strain energy change and developed strain energy based damage index for structures characterized by one dimensional beam and two-dimensional plate -like structures. Energy based methods successfully applied to identify location and quantification the damage in a storey steel frame or truss structures by Shi et al. [7-8]. To compute complex partial differential equations the differential quadrature method was used and the effectiveness of strain energy based damage index was significantly affected by resolution of mesh grid, the visibility the location of the damage increases with finer mesh grid [9-10]. However, change in the natural frequencies or mode shapes and its mode shape curvature from the first few operational deflection shapes of structure may not be sensitive to the effect of small cracks in the structure.

Thus, an alternative solution to attempts to solve this problem by using modern-techniques such as damage identification in structures based on spatial measures signal of the structure. The basic concept of this method is break down spatial measures signal or dynamic spatial signal of a structure in a series of mathematical functions so as to ascertaining specific characteristics of the structure. Therefore, in recent decades many researchers have been attracted towards the modern-type damage detection methods in structure because this method provided simple and feasible solution to the problems. Another main advantage of this methods compared to traditional-type is having cable to identify the tiny structural damages without base line data as reference. In recent years, an application of spatial wavelet theory were introduced to mode shape displacements for identification and localization of damage in beam and plate-like structures. Because wavelet has an ability to examine the local singularities in spatial signal with fine focus to furnish multiple levels of detail information of the signal. The main idea of damage detection in structures by using the wavelets is that determined the wavelet coefficients in full region of the beam primarily based on the numerical solution for the deflection of the beam, the damage location. Then, level was indicated with aid of a height wavelet transform modulus in distribution of the wavelet coefficients along the length of the beam [14]. Application of 2D-Continuous wavelet transform with Gaussian and reverse biorthogonal wavelet successfully applied in damage detection in beam and plate steel structures without knowledge of the characteristics of structure and the effect higher order modes towards structure damages analysed, concluded that application of wavelet with higher modes increases the visibility of damage and height of Modulus of wavelet transform [16-17]. Loutridis et al. proposed potential damage indicator and estimator to detect and evaluate the internal surface cracks by designed the multiple orthogonal wavelet coefficients and treated the boundary effects by using the biharmonic spline interpolation [19].

Unfortunately, significant draw back of the all methods stated above is that they required dynamic characteristics of the healthy structure as a base line. It is increases the experimental cost and consumed the huge amount of time. Thus, in the view of above consideration, this research more effort has been made to derive an approximately equivalent of healthy mode profiles from damaged mode profiles. Further, the effectiveness of the proposed method wavelet transform approach in detect the location and quantification of the damage demonstrated by operational mode shapes extracted from experimental and numerical analysis carried on 
single and double cracked aluminium cantilever beam.

\section{WAVELET ANALYSIS - METHODOLOGY}

\subsection{Continuous Wavelet Transformation}

A Wavelet Transform (WT) is a representation of continual time-domain by wavelets, which are the local basis functions of the signal. Wavelet Based Damaged Detection (WBDD) is more advantageous in detecting the local features of structure's signal at high frequencies or based on the scaled and translated features of wavelets (decomposition of signal). In the contest of damage detection, structure's signal such as mode shape, modal strain energy, mode shape curvatures, and mode shape curvature squares, etc. may be treated as the spatial signal. The WT has the greater ease in evaluating the non-periodic and unsteady erratic waves or signals. For a given one-dimensional signal the continuous wavelet transform can be illustrated as $[14,19]$.

$$
\psi f(t, s)=\frac{1}{\sqrt{s}} \int_{-\infty}^{\infty} f(x) \psi^{*}\left(\frac{x-t}{s}\right) d x
$$

Where, $\psi(t)$ is selected mother wavelet, $f(x)$ is the continuous wavelet transform of a signal. Here $\mathrm{s}$ and $\mathrm{t}$ are scale and position parameters.

\subsection{Discrete Wavelet Transformation}

In this manuscript, Discrete Wavelet Transform (DWT) is employed to evaluating and analyse wavelet coefficients of the spatial signals i.e. mode shapes and its derivatives in discrete resolution. Thus, it is more suitable for data compression and signal reconstruction. In the DWT case, it analyses the signal at different cut-off frequency bands with different resolutions by decomposing the signal into a coarse approximation and detailed information. The decomposition of the signal into different frequency bands is simply obtained by successive highpass and lowpass filtering of the time domain signal. Then, original signal is passed through a series of half-band high pass filters to analyse the high frequencies, and it is passed through a series of half-band lowpass filters to analyse the low frequencies.

Schematic diagram shows that decomposition spatial signal into three levels with wavelet details and approximations, Fig.1.

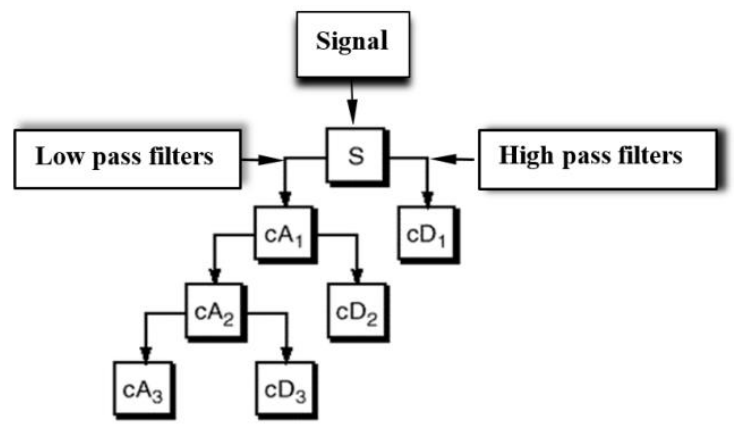

Fig. 1. Tree structure of decomposed spatial signal

Wavelet based damage detecting procedure, Fig.2:

1. Find the mode shapes or operational deflection shapes of vibrational structure,

2. Feed them to mother wavelet as spatial signal to detect singularities in given signal $f(x)$, Fig.2a,

3. Extract the wavelet coefficients of given signal of intact and damaged structure,

4. Plot the values of wavelet coefficients along the length of the beam for each scale of wavelet,

5. Examine the distributions of wavelet coefficients at each scale. A sudden change in distributions of wavelet coefficients identifies the damage location and estimation, Fig. 2 b.

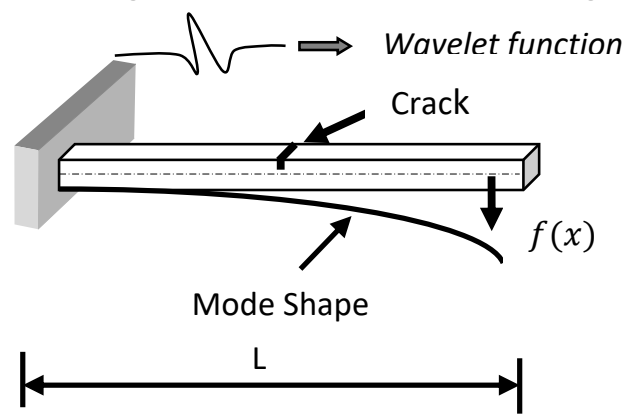

a) Geometry of the analysed cantilever beam

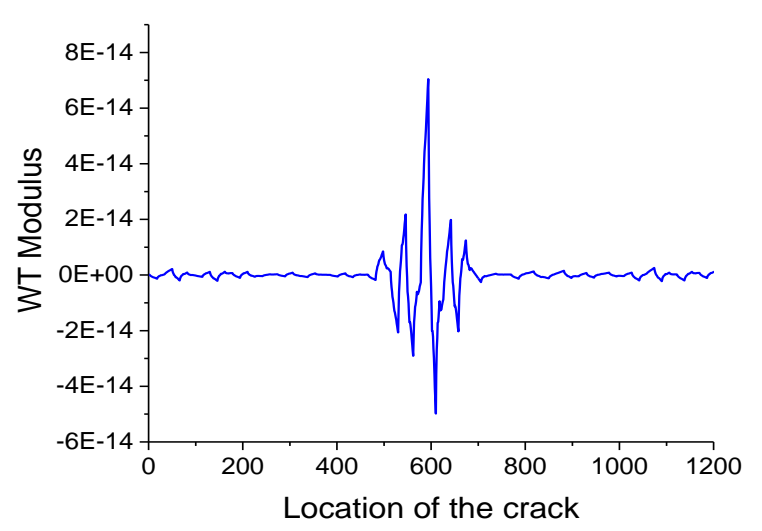

(b) Distribution of wavelet coefficients along the length of the beam

Fig. 2. Sketch showing the wavelet-based damage detection technique 


\section{NUMERICAL ANALYSIS OF A CANTILEVER BEAM}

Numerical analysis is performed using commercially available FEA software i.e. ANSYS 15.0. Solid element (Brick 8 node 185) is used to model an aluminium cantilever structural beam having dimensions i.e. width $B=0.025 \mathrm{~m}$, height $\mathrm{H}=$ 0.001 and length $L=0.8 \mathrm{~m}$, with hexagonal mapped meshing of elements. The boundary conditions used in Finite Element Modal Analysis (FEMA) are as same as in EMA. First Five vibration modes of structural beam are evaluated for damaged (single and multiple cracks) conditions. The comparison of natural frequencies obtained in EMA and FEMA are shown in Table 1. Damage has simulated as rectangular open transverse crack by reducing the stiffness of elements $10 \%, 20 \%$ and $30 \%$ of the beam at location of damage. Material properties of the beam aluminium beam 6061, i.e., Young's Modulus $E=70 \mathrm{G} \mathrm{Pa}$, density, $\rho=2,700 \mathrm{~kg} / \mathrm{m}^{3}$, Poisson's Ratio $u=0.3$.

\section{EXPERIMENTAL MODAL ANALYSIS (EMA) ON STRUCTURAL BEAM}

Experimental Modal Analysis (EMA) is conducted for damage detection in structural beam using Portable Digital Vibrometer (PDV-100), non-contact vibration measuring equipment. In EMA VibSoft software is used along with PDV-100 for data acquisition. The detailed experimental setup is shown in Fig.3. A structural beam of aluminium 6061 with the dimensions $0.8 \times 0.025 \times$ $0.01 \mathrm{~mm}^{3}$ is used in EMA. One end of the structural beam is clamped to replicate cantilever (fixed-free) boundary conditions as shown in Fig.3. 41 grid points along length mark the beam wise with the element length of $0.02 \mathrm{~m}$. Modal displacement data is collected from the measurements, which are further utilized to validate mode shape derived from numerical analysis. Two types of damage scenarios of beam are taken for the experimentation: single surface open crack at mid span of beam and two surface open cracks at $0.3 \mathrm{~m}$, $0.6 \mathrm{~m}$ locations along beam's length. The Schematic representation of damaged beams shown in Fig.4 and Fig.5. The cracks are formed using Electron Discharge Machining (EDM) with a depth of $1 \mathrm{~mm}$ in both the damaged cases. Same specifications of damages are taken for FEMA.

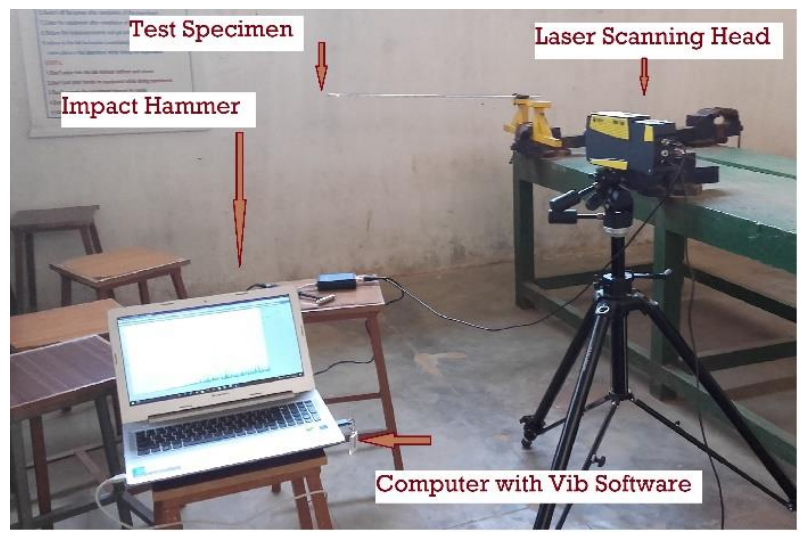

Fig. 3. Schematic layout of Experimental set-up

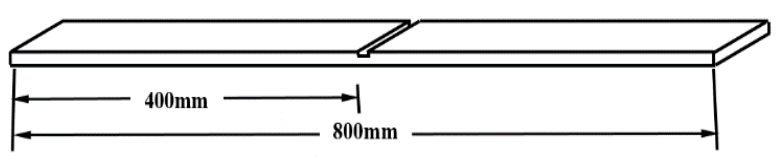

Fig. 4. Schematic Damaged (single crack) Beam: Damage location at $0.5 \mathrm{~L}$

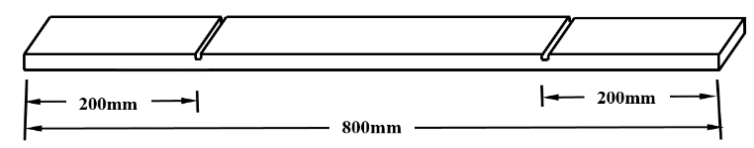

Fig. 5. Schematic Damaged (Double crack) Beam: Damage location at $0.25 \mathrm{~L}$ and $0.75 \mathrm{~L}$

\section{RESULTS AND DISCUSSIONS}

In the present research work, mode shape based damage identification method that is wavelet transform approach is used to accurate characterization of single and multi-cracks in beam like structure with composed undamaged mode profiles as a base line data. To assess the effectiveness of proposed approach, numerical modal analysis is employed on cantilever beam considering single and multi-damage location with various crack depth such as $10 \%, 20 \%$ and $30 \%$ height of the structural beam, experimental modal analysis on aluminum beam with Fixed-Free boundary conditions is also carried out to balance with the numerical results. First ten the natural frequencies of both numerical and experimental data with considering single and double cracked listed in Table 1. It is observed that change in frequency of first few fundamental frequencies almost negligible in this work, which indicates that compared to low frequency modes higher modes are more sensitive to damage [16-17].

First five modes obtained from the numerical analysis as shown in Fig.6. As indicated above, In 
order to validate and evaluate the performance of the proposed approach, results have been compared with an effective previously proposed method that was verified based on experimental results [14]. All above methods discussed in the literature are ascertaining location of the damage by data calculated absolute difference between the mode shapes of structure before and after the damage. To compute the data of healthy state of structure is laborious work or sometimes even impossible. To overcome this problem, curve fitting (CF) analysis is employed to obtain mode profiles of undamaged structure, the basic idea of this originated from damaged mode profiles, which are not showing any physical significant change in their deflected shapes before and after the damage of the structure. Fig.7 shows that operational mode shapes of mode one of cracked and un-cracked beam, dotted line indicates mode profile of healthy state of structure, which is generated by using curve-fitting analysis in MatlabR2015a. Cracked beam with varying crack depth from $0.1 \mathrm{~h}$ to $0.3 \mathrm{~h}$ are similar and even though crack depth increases mode shapes not exhibits any physical change in their mode profiles of different crack depths. Hence, damage cannot identify just looking at the mode profile itself. Alternative solution to attempt this problem is wavelet transform of special signal in which mode shapes are treated as special signal to input of DWT.

Table 1. Natural Frequencies of different damage cases

\begin{tabular}{|c|c|c|c|c|c|c|c|c|c|}
\hline \multirow{3}{*}{$\begin{array}{c}\text { Mode } \\
\text { No. } \\
\text { (i) }\end{array}$} & \multirow{2}{*}{\multicolumn{3}{|c|}{ Healthy Beam }} & \multicolumn{6}{|c|}{ Damaged Beam } \\
\hline & & & & \multicolumn{3}{|c|}{ Single Crack } & \multicolumn{3}{|c|}{ Multi Crack } \\
\hline & $\begin{array}{l}\omega_{i \text { EXP }} \\
(\mathrm{Hz})\end{array}$ & $\begin{array}{c}\omega_{\text {IFEM }} \\
(\mathrm{Hz}) \\
\end{array}$ & $\Delta_{i}(\%)$ & $\begin{array}{c}\omega_{i \text { EXP }} \\
(\mathrm{Hz})\end{array}$ & $\begin{array}{c}\omega_{i F E M} \\
(\mathrm{~Hz})\end{array}$ & $\Delta_{i}(\%)$ & $\begin{array}{c}\omega_{i E X P} \\
(\mathrm{~Hz})\end{array}$ & $\begin{array}{c}\omega_{i F E M} \\
(\mathrm{~Hz})\end{array}$ & $\Delta_{i}(\%)$ \\
\hline 1 & 12.68 & 13.12 & 0.03 & 12.46 & 12.97 & 0.04 & 12.32 & 12.62 & 0.02 \\
\hline 2 & 32.80 & 33.69 & 2.71 & 33.02 & 33.54 & 1.57 & 32.73 & 33.12 & 1.19 \\
\hline 3 & 87.26 & 88.45 & 1.36 & 79.31 & 80.07 & 0.95 & 79.30 & 80.65 & 1.69 \\
\hline 4 & 209.08 & 211.31 & 1.06 & 204.68 & 206.91 & 1.09 & 208.72 & 209.52 & 0.38 \\
\hline 5 & 285.48 & 286.45 & 0.34 & 281.00 & 282.46 & 0.51 & 241.38 & 242.97 & 0.65 \\
\hline 6 & 587.24 & 588.80 & 0.26 & 557.23 & 558.94 & 0.30 & 529.63 & 530.77 & 0.21 \\
\hline 7 & 594.98 & 596.86 & 0.31 & 586.70 & 588.63 & 0.32 & 566.96 & 568.58 & 0.28 \\
\hline 8 & 633.47 & 634.62 & 0.18 & 630.65 & 632.88 & 0.35 & 629.29 & 630.80 & 0.24 \\
\hline 9 & 1014.52 & 1015.44 & 0.09 & 995.81 & 996.78 & 0.09 & 991.43 & 992.94 & 0.15 \\
\hline 10 & 1151.86 & 1153.98 & 0.18 & 1130.02 & 1131.92 & 0.16 & 1115.71 & 1117.38 & 0.14 \\
\hline
\end{tabular}

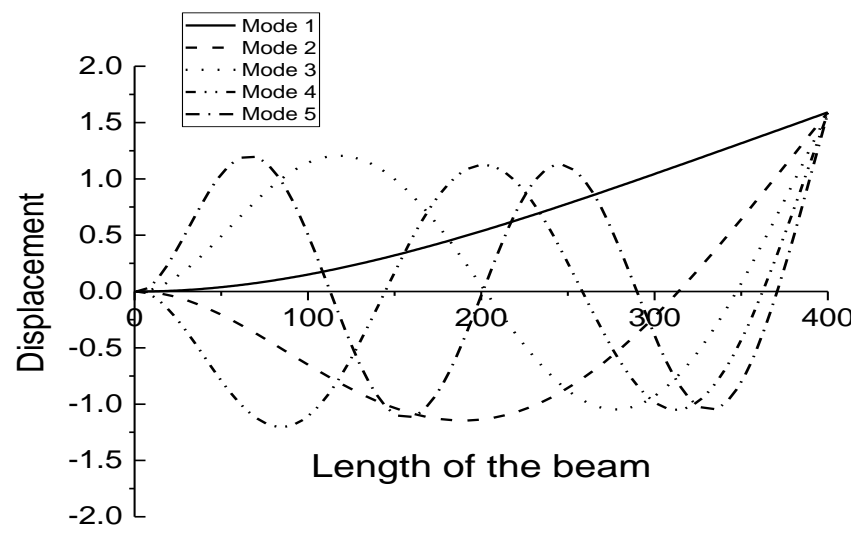

Fig. 6. First five numerical displacement modes shapes

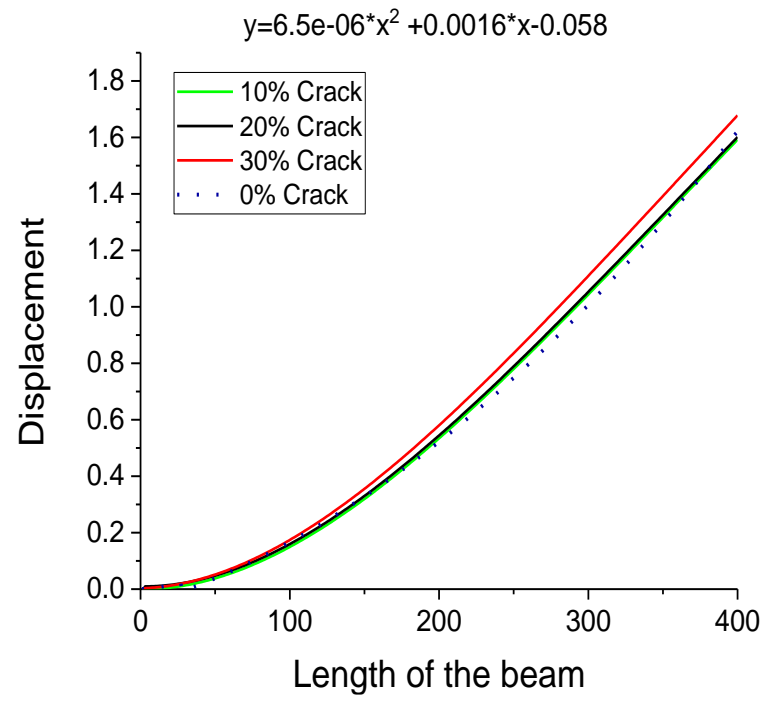

Fig. 7. First Mode profiles of healthy and cracked beam 
Material properties of double cracked aluminum cantilever beam are selected same as for beam with a single cracked beam as given in the Table 2.

Table 2 Material properties of double cracked beam

\begin{tabular}{lll}
\hline Name of the property & Magnitude & $\begin{array}{l}\text { Measured } \\
\text { units }\end{array}$ \\
\hline Young's modulus & $70 \times 10^{9}$ & $\mathrm{~N} / \mathrm{m}^{2}$ \\
\hline Density & 2,700 & $\mathrm{Kg} / \mathrm{m}^{3}$ \\
\hline Poison ratio & 0.3 & ---- \\
\hline
\end{tabular}

\subsection{Damage identification based on wavelet transform approach}

This section presents the basic characteristics of 1-Discrete Wavelet transform to be investigated using mode profiles generated from simulated cracked beams introduced in section 7.1. Wavelet tool available in MATLAB R2015a is used to evaluate the effectiveness of the proposed approach. Different types of wavelets are studied with each operational deflection shape to identify their efficiency in find the singularities in the spatial signal. It is observed that symlet family is a potential damage indicator, in wavelet family available in MATLAB wavelet toolbox. Thus, symlet is used to compute the different levels of decomposition of spatial signal. A sudden change or peaks in analyzed wavelet decomposition may be indicate the location of the damage or sudden change in the spatial signal. Hence, mode profile of damage or un-damage and even profile difference between undamaged and damage structure may not indicate significant difference. In this regard, different mode profiles in terms of various damage cases are analyzed by wavelet tool that is the more powerful in identifying damage.

\subsection{Case study 1: Identification of damage location in Single cracked beam}

In this case, 1-Discrete Wavelet transform is employed to identify location of the crack in single cracked aluminum beam structure. First, mode profiles corresponding to single cracked beam are treated as spatial signal for wavelet transform, which feed to 1DWT to ascertaining the location and quantification of a single crack in beam structure. Resulting wavelet coefficients are obtained from first five mode profiles are distributed along the length of the beam, which can be seen in plots in the Fig.8, 9, 10, 11 and 12 .
From the plots, it is clear that proposed wavelet is an efficient and effective potential damage indicator to locate the damages clearly by showing highest Wavelet transform Modulus at location of the crack. Potential advantage of DWT is having capability to identify the location of the damage with displacement mode shapes and even breathing cracks in the structural beams. It may not happen or even practically impossible with other traditional methods. As in case curvature mode shape method, higher modes are sensitive to the damage, it can be seen from values of WT Modulus of mode 1 , mode 2 and mode 3.

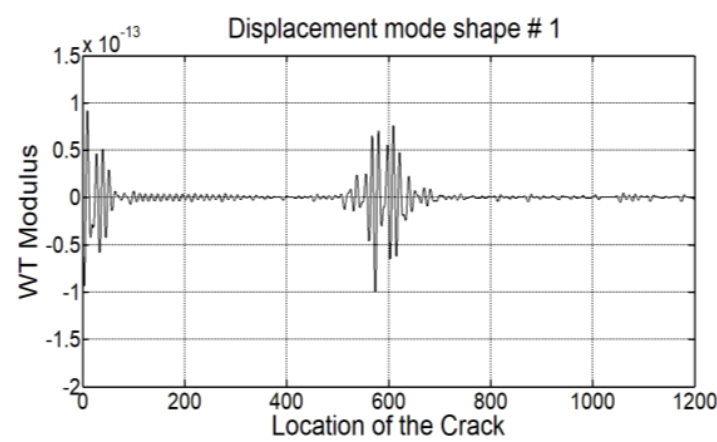

Fig. 8. $1^{\text {st }}$ Mode: DWT for displacement mode shape and curvature mode shape of single cracked beam

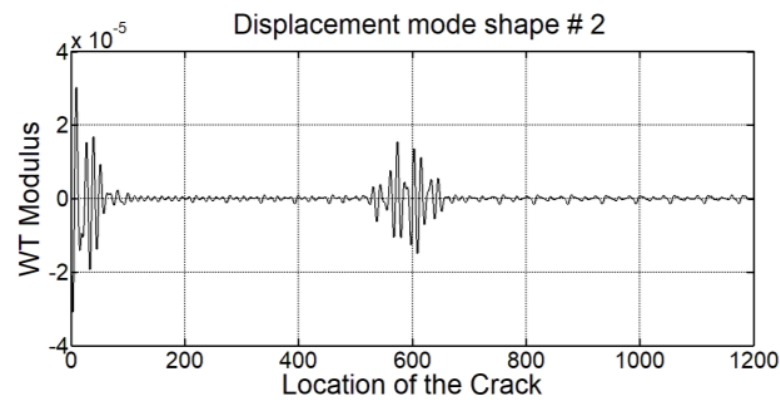

Fig. 9. $2^{\text {nd }}$ Mode: DWT for displacement mode shape and curvature mode shape of single cracked beam

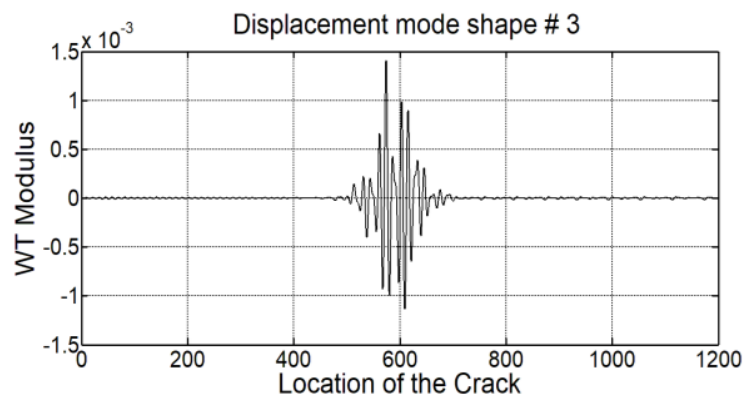

Fig. 10. 3rd Mode: DWT for displacement mode shape and curvature mode shape of single cracked beam 


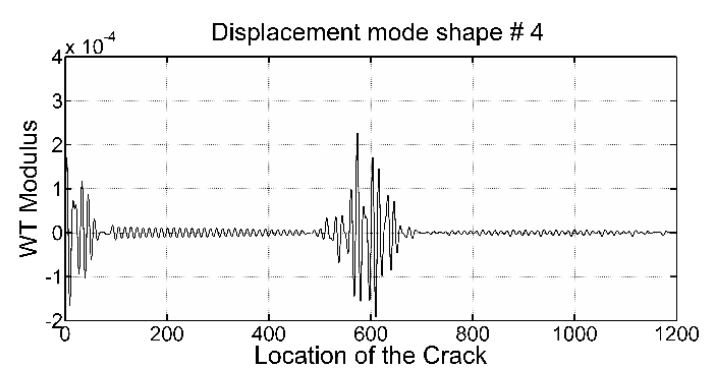

Fig. 11. 4th Mode: DWT for displacement mode shape and curvature mode shape of single cracked beam

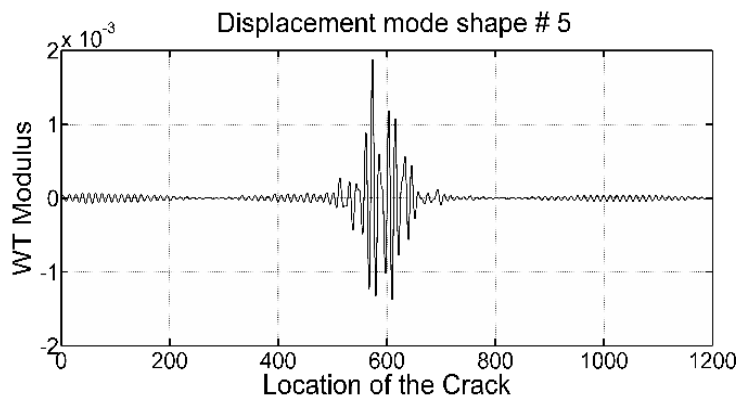

Fig. 12. 5th Mode: DWT for displacement mode shape and curvature mode shape of single cracked beam

\subsection{Case study 2: Identification of damage location in Double cracked beam}

In this section, aluminum cantilever beam with multiple crack locations are studied using DWT [19]. For illustration the proposed method a cracked cantilever beam, mode profiles are employed in curvature mode shape, same mode profiles are adopted for this analysis. Again, first five mode profiles from double cracked beam structure are transformed to same wavelet family i.e. symlet, which is used in single cracked mode profile transformation, to ascertaining the location and quantification of multi-cracks in double cracked beam. Resulting wavelet coefficients are obtained from first five mode profiles are distributed along the length of the beam. The distribution of wavelet coefficient of mode 1 and mode 2 along the length of the can be seen in plots in the Fig.13 and 14. It clearly indicates location of both cracks by displaying highest modulus values at damaged region in compared to un-located damage region. Again, this happen due to change in curvature of mode shape at location of damage. However, some of non-zero WT modulus values are observed at un-damaged location such as at fixed boundary this may be happened due to boundary conditions used in simulation analysis. This could be eliminate by using Free- Free boundary conditions and by expanding each mode outside the actual length of the beam using cubic spine interpolation
$[12,17]$. DWT is able to detect the exact location of damage using even first and second mode as shown in Fig.13 and 14.
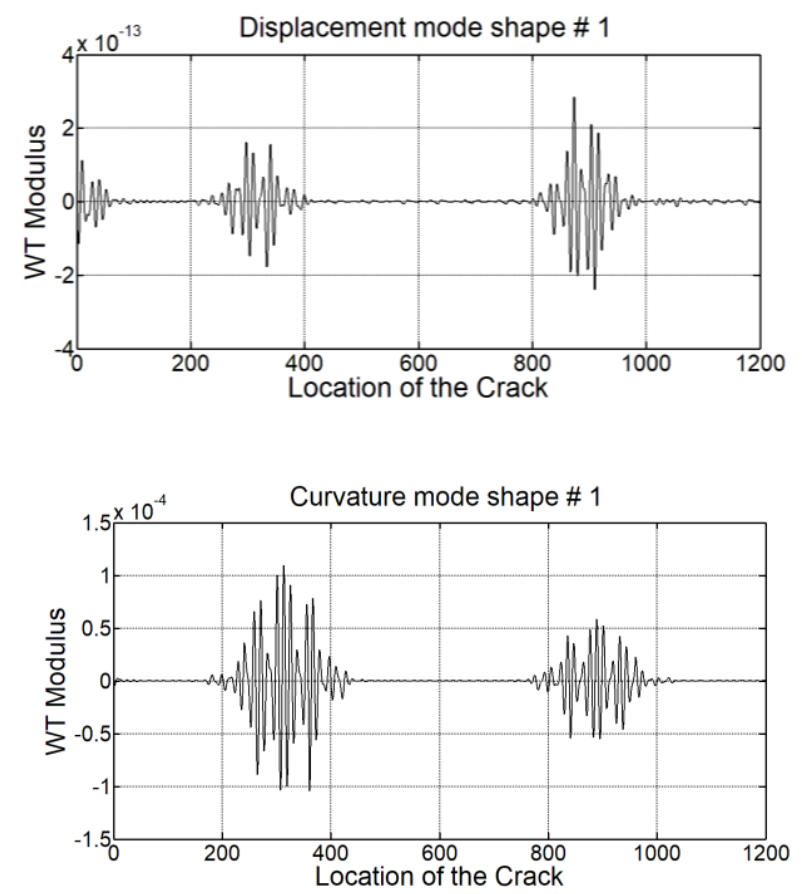

Fig. 13. $1^{\text {st }}$ Mode: DWT for displacement mode shape and curvature mode shape of double cracked beam
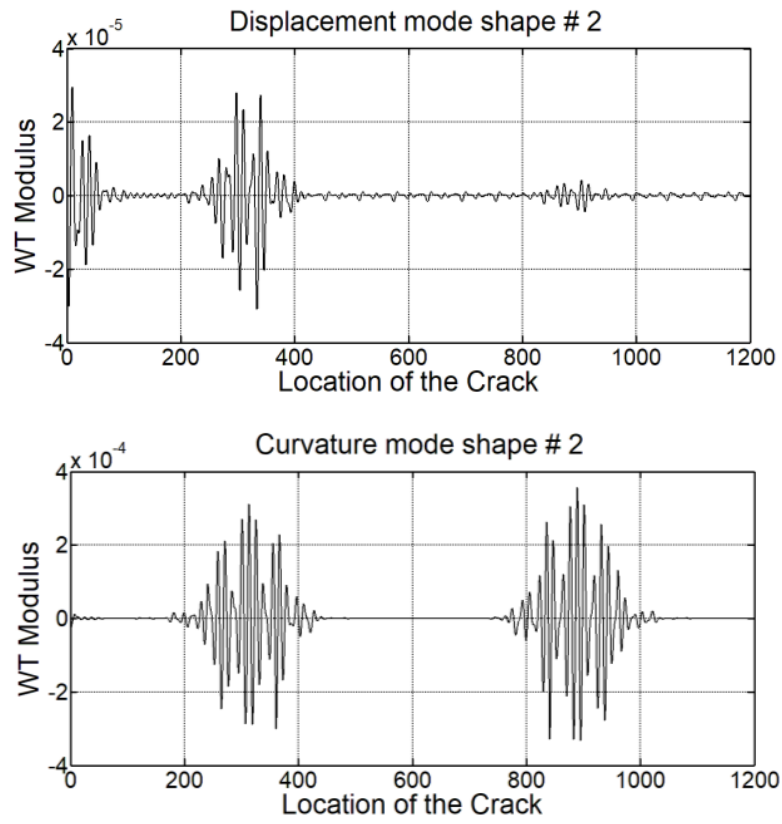

Fig. 14. $2^{\text {st }}$ Mode: DWT for displacement mode shape and curvature mode shape of double cracked beam

\subsection{Case study 3: Quantification of damage in single and double-racked cantilever beam}

Further, DWT is employed on first mode profile to identify the severity of damage in single and double cracked cantilever beam with different 
crack depths such as $10 \%, 20 \%$ and $30 \%$ height of the beam and crack located at $0.5 \mathrm{~L}$ in a single and, $0.25 \mathrm{~L}$ and $0.75 \mathrm{~L}$ in double cracked cantilever beams, corresponding results plot in Fig.15 and 16 . It clearly understand that the damage index obtained from the crake depth $0.3 \mathrm{H}$ showing highest peak value, which is indicated by the red color line, relative peak values corresponding to the $0.2 \mathrm{H}$ and $0.1 \mathrm{H}$ are indicated by the black and green color lines. This is occurs due to reduction of stiffness is increases with increase in the crack depth in structure.

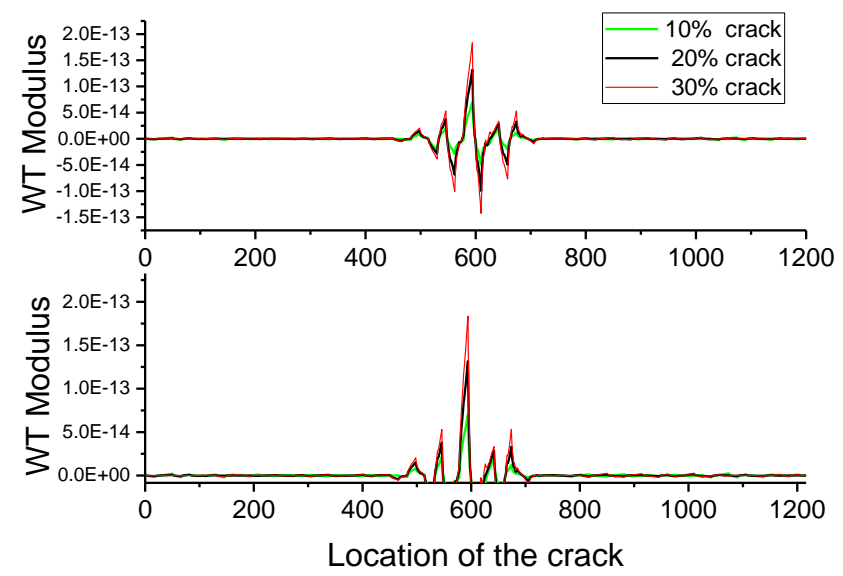

Fig. 15. Single cracked cantilever beam (crack location at depth $0.5 \mathrm{~L}$; crack depth from $0.1 \mathrm{~h}$ to $0.3 \mathrm{~h}$

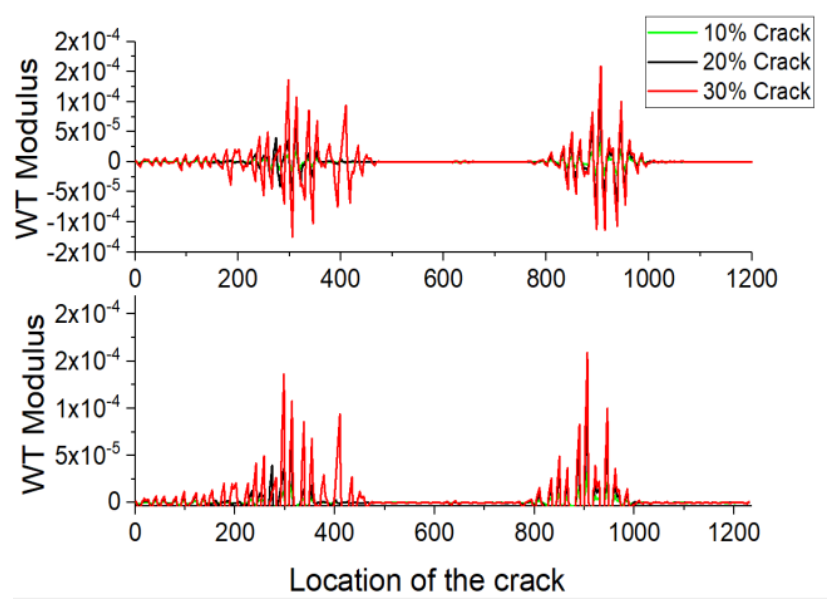

Fig. 16. Single Double cracked cantilever beam (crack location at depth $0.5 \mathrm{~L}$; crack depth from $0.1 \mathrm{~h}$ to $0.3 \mathrm{~h}$

\section{CONCLUSION}

This work mainly focuses on identification of location and quantification of the damage in single and double-cracked aluminium cantilever beam by using accurately composed undamaged mode profiles and measured damaged ones. Dynamic parameter of vibrational structural beam obtained from numerical and experimental modal analysis.
It was proposed to use modern signal analysis technique DWT method with obtained mode profiles as base line data. The effectiveness of the proposed methods is demonstrated by first five modes extracted from two aluminium cantilever beams containing single and double-cracks at different locations and depths. The results of research leads to following conclusion:

$>$ To reduce the time and experimental cost, mode shapes derived by the proposed approach can be conveniently used as reference data for the damage identification and estimation purpose;

> Further, Wavelet transformation is also performed to detect the damage in a single and multi-cracked beam. The main advantage of wavelet transform compared CMS based damage index is that this method has capability to identify the damage in the structure even with mode shape itself;

$>$ Wavelet transformation method is not required information regarding the healthy state of the structure as a reference data to detect damage.

> The apparent limitation of wavelet transform (WT) is that which requires mode shape measured with a relatively high spatial resolution. This was overcome by enhanced the signal using the cubic spline interpolation technique;

$>$ For the established damage index and WT Modulus, for higher mode profiles, the peak value of damage index and WT modulus is higher, which implies that higher mode profiles are more sensitive to the presence of the damage.

Worthy of noticeable point in the damage detection methods is that are requiring healthy data as the reference. In general, the baseline data may not be available or even impossible to obtain. However, the DWT method is performed based on base line data artificially derived from damaged mode profiles.

Further, study towards the application of the proposed approach to two-dimensional plate-like structures seems worthy of investigation. These related problems are intended to address in future work.

\section{REFERENCES}

[1] P. Cawley, R.D. Adams, Location of defects in structures from measurements of Natural 
frequencies. Journal of Strain Analysis for Engineering Design, 14 (2), 1979: 49-57.

https://doi.org/10.1243/03093247V142049

[2] P. Cawley, R.D. Adams, A Vibration technique for non-destructive testing of fibre composite structures. Journal of Composite Materials, 13 (2), $1979: 161-175$.

https://doi.org/10.1177/002199837901300207

[3] A.K. Pandey, M. Biswas, M.M. Samman, Damage Detection from changes in Curvature mode shapes, Journal of Sound and Vibration. 145 (2), 1991: 321-332.

https://doi.org/10.1016/0022-460X(91)90595-B

[4] S.W. Doebling, C.R. Farrar, M.B. Prime, D.W. Shevitz, Damage identification and health monitoring of structural and mechanical systems from changes in their vibration characteristics: A literature review, Research report No: LA-13070-MS, ESA-EA, Los Alamos National Laboratory. 1996.

https://doi.org/10.2172/249299

[5] S.W. Doebling, C.R. Farrar, M.B. Prime, A summary review of vibration-based damage identification methods. Shock and Vibration Digest, 30( 2), 1998: 91-105.

https://doi.org/10.1.1.57.9721

[6] P. Cornwell, S.W. Doebling, C.R. Farrar, Application of the strain energy damage method to plate-like structures. Journal of Sound and Vibration, 224 (2), 1999: 359-374.

https://doi.org/10.1006/jsvi.1999.2163

[7] Z.Y. Shi, S.S. Law, L.M. Zhang, Structural Damage Localization from Modal Strain Energy Change. Journal of Sound and Vibration, 218 (5), 1998: 825-844.

https://doi.org/10.1006/isvi.1998.1878

[8] Z.Y. Shi, S.S. Law, L.M. Zhang, Structural Damage Detection from Modal Strain Energy Change, Journal of Engineering Mechanics, 126 (12), 2000: 1216-1223.

https://doi.org/10.1061/(ASCE)07339399(2000)126:12(1216)

[9] H. Hu, B.T. Wang, C.H. Lee, J.S. Su, Damage detection of surface cracks in composite laminates using modal analysis and strain energy method. Composite Structure, 74 (4), 2006: 399-405.

https://doi.org/10.1016/i.compstruct.2005.04.020

[10] H.W. Hu, C. B. Wu, Non-destructive Damage Detection of Two Dimensional Plate
Structures Using Modal Strain Energy Method. Journal of Mechanics, 24 (4), 2008: 319-332.

https://doi.org/10.1017/s1727719100002458

[11] J. T. Kim, Y.S. Ryu, Damage identification in beam-type structures: frequency-based method vs mode-shape-based method. Engineering Structures, 25 (1), 2003: 57-67.

https://doi.org/10.1016/i.proeng.2017.02.023

[12] S. Rucevskis, M. Wesolowski, A. Chate, Vibration-based damage detection in a beam structure with multiple damage locations, Aviation. 13 (3), 2009: 61-71.

https://doi.org/10.3846/1648-7788.2009.13.61-71

[13] Y.J. Yan, L. Cheng, Z.Y. Wu, \& L.H. Yam, Development in vibration-based structural damage detection technique. Mechanical Systems and Signal Processing, 21 (5), 2007: 2198-2211.

https://doi.org/10.1016/i.ymssp.2006.10.002

[14] K. M. Liew, Q. Wang, Application of wavelet theory for crack identification in structures, Journal of Engineering Mechanics, 124(2), 1998: 152-157.

https://doi.org/10.1061/(ASCE)07339399(1998)124:2(152)

[15] Q. Wang, X. Deng, Damage detection with spatial wavelets. International Journal of Solids and Structures, 36 (23), 1999: 34433468.

https://doi.org/10.1016/50020 7683(98)00152-8

[16] M. Rucka, K. Wilde, Application of continuous wavelet transform in vibration based damage detection method for beams and plates. Journal of Sound and Vibration, 297 (3), 2006: 536-550.

https://doi.org/10.1016/i.jsv.2006.04.015

[17] M. Rucka, Damage detection in beams using wavelet transform on higher vibrational modes. Journal of Sound and Vibration, 42 (2), 2014: 339-417.

[18] E. Douka, S. Loutridis, A. Trochidis, Crack identification in beams using wavelet analysis. International Journal of Solids and Structures, 40 (13-14), 2003: 3557-3569.

https://doi.org/10.1016/S0020-7683(03)00147-1

[19] S. Loutridis, Douka. E, A. Trochidis, Crack identification in double-cracked beams using wavelet analysis. Journal of Sound and Vibration, 277 (4-5), 2004: 1025-1039.

https://doi.org/10.1016/j.jsv.2003.09.035 